\title{
Juventudes Rurais: Projetos de Emancipação Social
}

http://dx.doi.org/10.21527/2237-6453.2020.52.33-54

Recebido em: 25/9/2019

Aceito em: 28/2/2020

Joel Orlando Bevilaqua Marin ${ }^{1}$

\begin{abstract}
RESUMO
Este artigo analisa diferenciados projetos de jovens rurais para a construção de seus processos de emancipação social. 0 estudo de caso foi realizado em municípios do Território da Região Central do Rio Grande do Sul, com produção de dados qualitativos e quantitativos. Os jovens rurais vivenciam distintas problemáticas e constroem diferenciados projetos de emancipação social, que passam pela vinculação nas instituições escolares, incorporação no trabalho assalariado e reprodução social na agricultura familiar. A precariedade material e a desvalorização das condições de vida e trabalho na agricultura, limitam a permanência de jovens no meio rural e a construção social de sucessores na agricultura familiar.
\end{abstract}

Palavras-chave: Juventude rural. Migrações rurais. Desenvolvimento regional. Desenvolvimento territorial.

\section{RURAL YOUTH: SOCIAL EMANCIPATION PROJECTS}

\section{ABSTRACT}

The article analyzes rural youth projects for the construction of their processes of social emancipation. The case study was carried out in municipalities of the Territory of the Central Region of Rio Grande do Sul, generating qualitative and quantitative data. Rural young people experience different problems and build special social emancipation projects, which go through linking in school institutions, incorporation in paid work and social reproduction in family agriculture. Material precariousness and depreciation of living and working conditions in agriculture limit the permanence of young people in rural areas and the social construction of successors in family agriculture.

Keywords: Rural youth. Rural migration. Regional development. Territorial development.

\footnotetext{
${ }^{1}$ Doutor em Sociologia pela Universidade Estadual Paulista Júlio de Mesquita Filho (Unesp). Professor do Programa de Pós-Graduação em Extensão Rural da Universidade Federal de Santa Maria (UFSM). http://lattes.cnpq.br/2469734454387464. https://orcid.org/0000-00017438-7939. bevilaquamarin@gmail.com
} 
O objetivo deste artigo é analisar os diferenciados projetos de jovens rurais, filhos de agricultores familiares, residentes em municípios do Território da Região Central do Rio Grande do Sul, para a construção de seus processos de emancipação social. Para a consecução de tal objetivo, os projetos profissionais dos jovens rurais foram apreendidos em três grandes grupos, que perpassam pela continuidade dos estudos escolares, incorporação em trabalhos assalariados e sucessão na agricultura familiar. Fundamentado em perspectiva construtivista, compreende-se a juventude rural como construto histórico-social, variável no tempo e no espaço, que requer a análise dos contextos histórico-sociais e das relações sociais em que os jovens e suas famílias estão envolvidos. Tal perspectiva analítica requer estudos da realidade em que os jovens vivem, estudam e trabalham.

Na produção de dados para a análise de situação particular, a opção metodológica foi a realização de um estudo de caso, com recorte qualitativo e quantitativo. ${ }^{2}$ Os dados qualitativos foram obtidos por meio de entrevistas semiestruturadas dirigidas a 12 jovens rurais, selecionados segundo critérios não probabilísticos. Os dados quantitativos foram produzidos por meio de questionário. Para a amostragem quantitativa, intencionalmente construída, foram considerados os seguintes critérios: jovens integrantes de famílias de agricultores; faixa etária entre 16 e 29 anos de idade; e indicações de agentes de extensão rural atuantes na região. Os jovens rurais residem em 14 munícipios do Território Região Central do Rio Grande do Sul: ${ }^{3}$ Dilermando de Aguiar, Nova Esperança do Sul, Nova Palma, Silveira Martins, Restinga Seca, Dona Francisca, Mata, Cacequi, Quevedos, Agudo, Toropi, Unistalda, Tupanciretã e Jari. De acordo com dados do IBGE de 2010, a população de jovens rurais residente nesses municípios, com idade entre 16 e 29 anos, era de 8.046 pessoas, sendo $52,2 \%$ do sexo masculino e $47,8 \%$ do sexo feminino. A amostragem foi constituída por 191 jovens rurais, sendo $50,8 \%$ moças e $48,2 \%$ rapazes, $75,9 \%$ solteiros e $24,1 \%$ casados e $53,0 \%$ estudantes e $47,0 \%$ não estudantes.

Para efeitos de organização, inicialmente são apresentados conceitos necessários à compreensão da juventude rural como categoria marcada pela diversidade social e pelos desafios do ingresso na vida adulta. Nas três seções subsequentes, particularizam-se diferenciadas estratégias de jovens rurais para construir seus processos de emancipação social e ingresso na vida adulta, centralizando a análise na vinculação em instituições escolares, na incorporação no mercado de trabalho assalariado e na viabilização da sucessão na agricultura familiar.

\footnotetext{
${ }^{2}$ Os dados da pesquisa foram produzidos a partir de um projeto de extensão universitária desenvolvido em parceria entre a Emater/RS, Universidade Federal de Santa Maria (UFSM) e Instituto Federal Farroupilha (IFFar), com objetivos de conhecer aspectos da realidade da juventude rural da região central gaúcha e elaborar estratégias de inclusão social de jovens rurais (Emater/RS, UFSM, IFFar, 2017; PICOLOTTO; MARIN, 2018). Nesse projeto, o autor participou em todas as etapas de desenvolvimento, daí que os agentes responsáveis pela parceria deram autorização para aprofundamento da análise dos dados, com o compromisso ético de compartilhá-los com jovens rurais e demais atores comprometidos com as causas juvenis rurais.

${ }^{3}$ O Território Região Central do Rio Grande do Sul engloba 33 municípios e uma área de $32.457,00 \mathrm{~km}^{2}$. Além dos municípios pesquisados, é constituído por Capão do Cipó, Faxinal do Soturno, Formigueiro, Santiago, São João do Polêsine, São Martinho da Serra, Vila Nova do Sul, Itaara, Ivorá, Jaguari, Novo Cabrais, Paraíso do Sul, Pinhal Grande, Santa Maria, São Francisco de Assis, São Pedro do Sul, São Sepé, São Vicente do Sul e Cachoeira do Sul (MDA, 2016). Em 2010, segundo dados do IBGE, a população do território era de 647.769 habitantes, posto que 19,44\% viviam no meio rural.
} 


\section{JUVENTUDES RURAIS: UMA APROXIMAÇÃO TEMÁTICA E CONCEITUAL}

Desde meados da década de 90 do século 20, a juventude rural tornou-se tema de interesse de múltiplos agentes sociais. Representantes de movimentos sociais rurais, agentes de desenvolvimento e pesquisadores multidisciplinares, sob diferenciados interesses e perspectivas, mobilizaram-se para romper com a "invisibilidade social" da juventude rural e para reconhecê-la como categoria social portadora de necessidades, reivindicações e potencialidades nos processos de desenvolvimento. Em pontos de confluência, defendiam a promulgação de aparatos jurídicos e a edição de políticas públicas específicas para as gerações juvenis rurais, atribuindo compromissos não só ao Estado, mas também à sociedade e às famílias, no sentido de conferir apoio financeiro, educacional e produtivo, para viabilizar processos de sucessão hereditária na agricultura familiar.

Nas juventudes rurais, como destacado por Ferreira e Alves (2009), foram depositadas as expectativas de continuidade do mundo rural e da reprodução social do campo e, mais especificamente, da agricultura familiar. A contínua migração juvenil, portanto, foi percebida como fator limitante da reprodução da agricultura familiar e do desenvolvimento territorial, enquanto a permanência dos jovens no meio rural tornava-se condição fundamental para a continuidade da agricultura familiar. Na medida em que a agricultura familiar conquistou reconhecimento social, como categoria socioprofissional dotada de direitos e de políticas públicas, a juventude rural também se tornou uma categoria social de mobilização e de luta para múltiplos agentes afiliados aos órgãos de representação política, às instituições de pesquisa e desenvolvimento territorial e aos movimentos sociais rurais, bem como aos movimentos juvenis rurais. Nesse sentido, a luta pelo reconhecimento social e pela defesa de direitos da juventude rural também integrou as pautas e lutas pela continuidade da agricultura familiar, daí que a construção da problemática da sucessão hereditária, pela inserção social e produtiva das gerações juvenis rurais, é caudatária dos processos de institucionalização da categoria socioprofissional designada agricultura familiar.

$\mathrm{Na}$ análise de Neves (2007), a agricultura familiar é compreendida como uma construção social desencadeada por múltiplos agentes sociais, vinculados aos movimentos sociais de agricultores, instituições nacionais e internacionais e pesquisadores multidisciplinares, mobilizados em defesa das causas da agricultura familiar. As lutas para reconhecimento público da agricultura familiar visaram, fundamentalmente, à institucionalização de leis e de políticas públicas facilitadoras de acesso ao crédito rural, serviços de extensão rural, mercados institucionais, moradia, entre outros benefícios.

Na medida da objetivação de direitos e de políticas públicas para a agricultura familiar, a sucessão hereditária tornou-se questão relevante nos processos de desenvolvimento territorial, pois os jovens rurais passaram a representar o futuro da agricultura familiar, reproduzindo valores supostamente a ela associados: produção de alimentos, segurança alimentar, geração de emprego e renda, continuidade dos modos de vida e ocupação populacional de espaços rurais. No entendimento de agentes comprometidos com pautas da agricultura familiar, portanto, os benefícios conquistados pelos agricultores adultos deveriam estender-se às jovens gerações rurais. 
A problematização da juventude rural e a institucionalização de políticas públicas, situam-se em contexto sociopolítico nacional favorável à atuação de diferentes representantes de movimentos sociais, mediadores políticos e pesquisadores, que tiveram oportunidades de ocupar cargos em instâncias estatais, especialmente desde o primeiro governo de Luiz Inácio Lula da Silva (BARCELLOS, 2017). As providências foram delineadas pelos marcos da intervenção estatal, com vistas a conferir visibilidade e reconhecimento à juventude rural como categoria social portadora de direitos e beneficiária de políticas públicas, especialmente de acesso a terra, crédito rural e formação técnico-profissional. Resultados dessas lutas também consubstanciaram-se na promulgação de dispositivos legais, a exemplo do Estatuto da Juventude - Lei № 12.852, de 5 de agosto de 2013 - e do Plano Nacional de Juventude e Sucessão Rural - Decreto no 8.736, de 3 de maio de 2016 (BRASIL, 2013, 2016).

Com tais investimentos coletivos, a juventude rural foi se constituindo como uma categoria social específica da população rural brasileira, atualmente definida entre os 16 e 29 anos de idade. A noção de juventude apresenta demarcadores biológicos e etários, que, como alertou Bourdieu (2011), são sempre manipuláveis, servindo para enquadramentos institucionais e "divisões dos poderes". No estudo da juventude, portanto, Bourdieu (2011) propugna análises da diversidade de formas de inserção econômica, política e social e da complexidade das condições objetivas e subjetivas dos contextos familiares e histórico-sociais em que os jovens vivem. Sob esse prisma, a juventude torna-se uma categoria relacional, o que implica estudos situados nos diversos contextos econômicos, políticos, histórico-sociais, em seu vínculo com recortes de classe social, família, gênero, inserções laborais e agregações escolares, e em suas relações com aspectos objetivos e subjetivos da vida dos jovens em sociedade.

Igualmente fundamentado em perspectiva construtivista, Feixa (2006a, 2006b) compreende a juventude como um constructo histórico e sociocultural relativo no tempo e no espaço. Para fundamentar tal postulado teórico-metodológico, o autor propõe a análise das diferenciadas formas de viver a condição juvenil, os distintos processos de transição sociocultural e diversas representações de juventude, que se apresentam variáveis de uma sociedade para outra e até mesmo dentro de uma mesma sociedade, ao longo dos processos históricos. Ainda segundo Feixa (2004), existem múltiplas maneiras de viver, expressar e perceber a juventude, pois tanto no passado quanto no presente diferenciadas sociedades construíram condições sociais e imagens juvenis específicas para inserir os jovens e demarcar seus processos de transição socioculturais.

A agricultura familiar, segundo Schneider (2006), é uma categoria socioprofissional marcada pela diversidade social nas formas de apropriação dos meios de produção, de organização das atividades produtivas e laborais, de estruturação das dinâmicas territoriais, de construção de estratégias de reprodução familiares e coletivas e de representação de seu universo cultural e simbólico. A juventude rural, vinculada à agricultura familiar, por extensão, também comporta uma ampla diversidade social. O estudo da juventude rural, portanto, também requer a compreensão de elementos objetivos da realidade, que passa pelas formas de organização da produção e do trabalho familiar, das relações com a natureza e das estratégias de inserção nos espaços mercantis, bem como pela compreensão das dimensões culturais e simbólicas que orientam as visões de mundo, as relações de trabalho, de parentesco, de geração e de gênero, além das 
afiliações institucionais e atuações políticas. A apreensão da complexidade de situações produtivas, laborais e socioculturais nos auxilia a compreender a condição juvenil, conforme apontam Abramo (2007), Wanderley (2007), Carneiro (2007) e Castro (2007), não como um padrão de "ser jovem" ou como uma idealização, mas a partir da diversidade de maneiras de se viver, conceber a juventude e reconhecer a existência de diferenças e desigualdades sociais entre os jovens rurais, mesmo que pertencentes à categoria de agricultores familiares.

Sob essa perspectiva, particularizando a situação contemporânea do Território da Região do Rio Grande do Sul, entende-se que os jovens rurais vivenciam distintas problemáticas e constroem diferenciados processos de autonomização social, que passam por diversificados investimentos pessoais e familiares, inserções laborais e institucionais e acesso às políticas públicas. A noção de autonomia, segundo Sant'Ana (2009), faz referência à capacidade de os sujeitos sociais imprimirem orientações às próprias ações e ideias, com certa independência ante os outros indivíduos, a comunidade e as instituições sociais. De acordo com Pappámikail (2009), as noções de autonomia e emancipação são indissociáveis, daí que o conceito de autonomia insere-se no conceito de emancipação, suscitando a análise de aspectos da realidade que posicionam o afastamento, ainda que relativo, dos jovens em relação às famílias de origem. Borges e Magalhães (2009, p. 43) observam que a construção social da autonomia indica uma transição para a idade adulta, cujos principais sinalizadores são "a saída da casa da família de origem, o investimento em um trabalho ou uma formação profissional, com a entrada no mercado de trabalho, a independência financeira, a autonomia e, posteriormente, a possibilidade de formar seu próprio núcleo familiar".

$\mathrm{Na}$ avaliação de contextos socioeconômicos e familiares marcados por diversas possibilidades e limitações, os jovens procuram assimilar certos recursos tecnológicos e viabilizar vinculações institucionais e laborais para garantir sua inserção positiva na sociedade e construir a autonomia social. Independentemente das distintas tessituras de emancipação, os jovens rurais pesquisados procuram interconectar-se com o mundo contemporâneo. Por tal razão, em depoimentos orais, jovens rurais revelam seu desejo e satisfação em apropriar-se de tecnologias e serviços facilitadores de acesso às informações e conhecimentos, especialmente o telefone móvel e a internet. Em termos quantitativos, do universo de 191 pesquisados, 97\% dos jovens rurais têm aparelhos celulares e $80 \%$ utilizam serviços de internet, posto que $51,8 \%$ acessam nas residências, 17,8 nas escolas e $10,8 \%$ nos telecentros ou nos locais de trabalho. A expansão dessas tecnologias de informação e comunicação contribuiu para mudar valores, percepções de tempo e espaço dos jovens rurais. Os referenciais de localidade e comunidade, marcantes em décadas anteriores, são transformados pelas noções de maior amplitude, mobilidade e agilidade para adentrar em outros mundos, percebê-los e vivenciá-los de formas diferenciadas. Os jovens rurais facilmente percebem que o mundo não está restrito aos conhecimentos transmitidos pelos pais ou professores nem às visões e possibilidades acenadas pela vida no meio rural. Nesse sentido, as tecnologias de comunicação e informação também interferem na socialização da juventude rural, na medida em que facilitam as interconexões sociais e ampliam visões de mundo. Longe do estereótipo de sujeitos atrasados, conservadores ou desinformados, nesse território, associados à 
imagem pejorativa de "colonos", temos jovens rurais que lutam, por meio de estratégias e recursos distintos, para conquistar posições sociais mais valorizadas e ocupações laborais mais bem remuneradas, contrapondo-se àquele contexto vivido por seus familiares.

Pelo exposto, a autonomia passa pela perspectiva profissional e financeira, e também pela afirmação de sujeitos sociais, que recorrem a certos recursos técnicos, estratégias sociais e concepções de mundo para orientar seus projetos de vida. Para efeitos deste estudo, são tomadas como referências de análise as estratégias que perpassam pela continuidade de estudos escolares, incorporação em relações assalariadas e sucessão hereditária na agricultura familiar, como principais sinalizadores da construção social da autonomia de jovens rurais pesquisados no território central gaúcho.

\section{JOVENS RURAIS E ESTUDOS: TRANSPOSIÇÕES DA CONDIÇÃO DE AGRICULTOR FAMILIAR}

No território em estudo, desde meados do século 20, a instituição escolar ganhou importância crescente nos processos de socialização das gerações juvenis rurais. Tanto os jovens rurais quanto suas famílias valorizam o ensino escolar como estratégia privilegiada para "melhorar de vida". A melhoria das condições de vida representa projetos de ascensão social, pela inserção em outras ocupações laborais mais valorizadas e mais bem remuneradas, vislumbradas fora da agricultura familiar. Na viabilização desses projetos individuais e familiares, concorrem positivamente a expansão das redes de ensino de nível médio e superior, sejam públicas ou privadas, embora sempre demandem consideráveis investimentos financeiros da família e esforços individuais dos jovens rurais estudantes.

Nas últimas duas décadas, na região em estudo, cresceu consideravelmente o número de instituições públicas e privadas, ${ }^{4}$ além das alternativas criadas pelo ensino a distância, que chegou junto com a expansão das redes de internet no meio rural. A ampliação e a interiorização das redes de ensino aumentaram consideravelmente as possibilidades de conquista de vagas em cursos de nível médio ou superior, tornando mais factível o sonho dos estudos escolares para os jovens rurais e, de maneira especial, para as jovens rurais (MARIN, 2018)..

Em pesquisas sobre contextos da agricultura familiar do Rio Grande do Sul, Carneiro (2001) e Brumer (2004) evidenciaram que as jovens rurais tendem a atribuir grande valor ao ensino escolar e ao trabalho assalariado, não somente pela viabilização de inserções positivas no mercado de trabalho e de construção de seus processos de emancipação pessoal, mas também em decorrência das desigualdades na escolha do sucessor e na partilha da herança familiar, pelo costume em privilegiar os filhos homens como sucessores e herdeiros da unidade de produção familiar. Ademais, as jovens rurais aspiram a inserções em ocupações laborais fora da agricultura como contraponto à

\footnotetext{
${ }^{4}$ Em municípios do Território da Região Central do Rio Grande do Sul estão instalados a Universidade Federal de Santa Maria (UFSM), o Instituto Federal Farroupilha (IFFar), o Colégio Politécnico da UFSM, o Colégio Técnico Industrial de Santa Maria (CTISM), a Universidade Estadual do Rio Grande do Sul (Uergs), a Universidade Regional Integrada do Alto Uruguai e das Missões (URI), a Faculdade Metodista de Santa Maria (Fames), a Faculdade Palotina de Santa Maria (Fapas), o Centro Universitário Franciscano (Unifra), a Faculdade de Direito de Santa Maria (Fadisma), a Universidade Luterana do Brasil (Ulbra), a Faculdade Integrada de Santa Maria (Fisma), a Faculdade Antônio Meneghetti, entre outras instituições de Ensino Técnico e Superior que operam com a modalidade de ensino a distância.
} 
desvalorização do trabalho doméstico e, por extensão, dos trabalhos desempenhados pelas mulheres na unidade produtiva. Embora proporcionem bem-estar à família e contribuam na composição da renda familiar, os trabalhos das mulheres e, em específico, das jovens, são socialmente percebidos como "ajuda", portanto desvalorizados. Na hierarquia familiar, conforme estudos de Paulilo (2017) em contextos de Santa Catarina, o homem ocupa-se de trabalhos socialmente valorizados, em virtude de sua posição de chefe de família e responsável pela reprodução do grupo familiar, enquanto a mulher e os filhos desempenham os trabalhos domésticos e os considerados "leves" ou "ajudas". Tal posição hierárquica e desvalorização dos trabalhos domésticos geram, portanto, insatisfação das mulheres e das jovens com a vida rural.

Na região pesquisada, os jovens rurais percebem os estudos escolares como alternativas plausíveis para a sua inclusão em posições socialmente valorizadas. Conforme dados quantitativos, do total de 191 jovens rurais, 52,40\% continuam os estudos escolares; entre esses, $11 \%$ estavam matriculados no Ensino Fundamental, 57\% no Ensino Médio, 14\% no Ensino Técnico, 17\% no Ensino Superior e 1\% no ensino de Pós-Graduação. Na medida em que os estudos se tornam os principais investimentos de projetos profissionais, os jovens distanciam-se dos trabalhos familiares, não somente em decorrência da maior exigência de tempo e dedicação aos estudos, mas também pelos necessários deslocamentos espaciais para as cidades com instituições de ensino. Weisheimer (2013), em estudo sobre projetos de jovens agricultores da região do Recôncavo baiano, notou a existência de uma relação inversa entre a continuidade dos estudos escolares e o projeto de reprodução da condição de agricultor familiar, identificando maior recusa em ser agricultor entre os jovens rurais estudantes do que entre os jovens que não continuavam os estudos escolares. Paulo (2014, p. 246), em pesquisa no município pernambucano de Orobó, constatou situação semelhante: "ficam na atividade agrícola os jovens que não estão inseridos no sistema de ensino".

Dados os compromissos escolares no Território da Região Central do Rio Grande do Sul, os jovens rurais tornam-se ajudantes eventuais no trabalho familiar, nos finais de semana, feriados e férias escolares. Não são incomuns, contudo, relatos de jovens que se dedicam exclusivamente aos estudos escolares. Nessas situações, os pais valorizam o ensino escolar e estimulam seus filhos exclusivamente aos estudos, dispensando-os dos trabalhos, mesmo que essa decisão implique sobrecargas laborais. O sacrifício do trabalho na unidade familiar torna-se a condição para proporcionar aos filhos outras formações profissionais, na expectativa de que estes não repitam a mesma sina dos pais. Notam-se, portanto, mudanças na forma de organização das famílias implicadas na dissociação da unidade familiar e da unidade produtiva. Esses novos arranjos familiares indicam que a unidade produtiva e a unidade familiar nem sempre encerram irrestritas equivalências, especialmente em contextos de restrição das condições de reprodução dos agricultores familiares e de projeção de outras formas de inserção sociolaboral.

Por tais razões, em depoimentos de jovens entrevistados, são comuns visões depreciativas da profissão de agricultor ou agricultora. Os jovens e, sobretudo, as jovens, não somente questionam as condições de agricultor ou agricultora familiar, mas também reafirmam o valor dos estudos na conquista de melhores formações educacionais e profissionais. O estudo possibilita, enfim, tornar-se "alguém na vida" e acompanhar as mudanças sociais, conforme depoimento oral: "O estudo é essencial pra ser alguém 
na vida. Sem estudo a gente não é nada, até porque a gente tá vivendo num país que, se a gente não estuda, a gente fica pra trás" (Luciano, 19 anos, Agudo). "Ser alguém na vida" significa a grande aspiração pela autonomia, que passa pelas questões financeiras, mas, fundamentalmente, por um projeto de construção de um agente produtivo autônomo, com reconhecimento e valorização social. A expressão, geralmente naturalizada, também é refletida pela impossibilidade de objetivação da reprodução dos agricultores familiares, aos quais resta o pesado, cansativo e desvalorizado trabalho agrícola, existente nas relações de integração agroindustrial. Em síntese, os jovens rurais percebem os estudos escolares como estratégias privilegiadas de ascensão social, em contextos de limites da reprodução familiar de agricultores, conforme depoimento:

Com certeza, os estudos são e estão sendo importantes para mim. Se eu não tivesse um grau de estudo já não estaria aqui no trabalho hoje. No meio rural tem serviço pra sempre se quiser, porque, quem não planta, trabalha de peão em outras propriedades. Agora pra arrumar um trabalho na cidade tu já tem que ter o estudo. Para a gurizada que termina o Ensino Médio e quer vim pegar um trabalho na cidade está complicado. Ainda mais hoje em dia, com a crise e o desemprego está complicado (Adriana, 19 anos, Agudo).

Alguns jovens percebem a importância dos estudos ao disputar empregos ou mesmo enfrentar as ameaças de desemprego, enquanto outros colocam em seu horizonte o ingresso em instituições de ensino técnico, superior e até mesmo de Pós-Graduação como caminho para a constituição como trabalhador autônomo e qualificado. Eles, portanto, submetem-se a viagens diárias para garantir frequência escolar ou a migrações para as cidades que ofertam cursos técnicos e superiores.

Mesmo que os acessos à qualificação profissional sejam ampliados e facilitados em relação às décadas anteriores, os estudos implicam, tanto para os jovens quanto para suas famílias, sacrifícios e dispêndio de tempo e recursos financeiros. Para garantir a frequência, alguns jovens rurais transferem-se para as cidades, embora tal decisão implique despesas com habitação, transporte, alimentação, mensalidades - no caso de instituições privadas de ensino -, entre outras. Para custear essas despesas, 5,1\% dos jovens rurais estudantes trabalham como assalariados, 3,0\% realizam estágios remunerados e 5,2\% acessam o Programa de Assistência Estudantil. Valendo-se de políticas públicas estudantis ou mesmo de trabalhos assalariados, esses jovens rurais dão continuidade aos seus processos de escolarização, de nível técnico ou superior, em busca de conhecimentos e de qualificação profissional. Assim, para as parcelas de jovens rurais pesquisados, os estudos e as migrações são estratégias de constituição do agente produtivo autônomo, fundamentadas em princípios morais de valorização da autonomia pessoal pelo trabalho e na aspiração de não repetir a profissão dos pais.

Por essa razão, o direito à mobilidade e ao transporte configura questão relevante, especialmente para os jovens rurais estudantes. Em relatos orais, eles tecem críticas contundentes à falta de zelo do poder municipal na manutenção e reparação das estradas de chão, que interligam suas residências às vias asfaltadas e às cidades. As denúncias estendem-se aos meios de transporte público, em decorrência da redução das linhas de 
ônibus, má qualidade das frotas e irregularidade de horários. ${ }^{5}$ No encaminhamento de soluções para esses problemas, as famílias e os jovens rurais investem na aquisição de seus próprios meios de transporte: do total de 191 pesquisados, 75,4\% dispõem de carros, $37,7 \%$ de motocicletas e 6,3\% de bicicletas. Esses meios de transporte particulares são percebidos como facilitadores dos deslocamentos espaciais para estudos, trabalho e lazer, além de poderosos recursos viabilizadores de autonomia pessoal.

Para os jovens rurais estudantes que permanecem na residência dos pais, a viabilização de meios de transporte torna-se questão fundamental. Para equacionar esse problema, em Agudo, jovens universitários fundaram uma associação com reconhecimento jurídico, a fim de facilitar a contratação de empresas de transporte, definir os roteiros e horários conforme as necessidades e, sobretudo, reduzir os custos do transporte. Em outra frente, esses estudantes passaram a reivindicar o passe livre do transporte público, respaldados pelo direito à educação, conforme depoimento oral:

Pro Ensino Superior, eu acho que tinha que ter um incentivo maior em verbas do passe livre. Mas essas verbas, não sei por que, não são bem direcionadas e não vêm pra nós, alunos. Isso é uma questão que hoje a gente tá debatendo bastante na nossa Associação de Estudantes Universitários (Luciano, 19 anos, Agudo).

Na problematização sobre o uso de recursos públicos, esses jovens rurais -identificados como estudantes - organizaram-se na luta pelo direito à mobilidade espacial e ao transporte público, agregando-se ao coro de protestos do Movimento Passe Livre, desencadeado em centros urbanos no ano de 2013, cujos principais protagonistas foram jovens. O questionamento do destino de recursos públicos e a reivindicação de passe livre expressam a luta pelos direitos de ir e vir, de estudar e de exercer a cidadania. Esses embates tornam-se, em suma, significativos espaços de afirmação como sujeitos de direitos e de emancipação pessoal e coletiva.

Enfim, parcelas significativas de jovens rurais investem nos estudos, fundamentados na crença de que a escola é lugar privilegiado para a construção de trajetórias socioprofissionais fora da agricultura familiar. A escolarização prolongada e os diplomas de nível técnico ou superior são percebidos pelos jovens rurais e, especialmente, pelas jovens rurais, como caminhos mais rápidos e seguros para tessituras da autonomia pessoal e da ascensão social.

\section{JOVENS RURAIS ASSALARIADOS: LIMITES DA REPRODUÇÃO FAMILIAR DE AGRICULTORES}

Não obstante a crescente valorização dos estudos escolares, o trabalho como necessidade, valor e identidade social ainda configura questão central nos projetos de jovens rurais pesquisados. De acordo com Wanderley (2007), a condição inerente aos agricultores familiares de proprietários e de trabalhadores do estabelecimento produtivo, orienta os processos de socialização dos jovens não apenas na família ou na comunidade de pertença, mas também na sociedade no sentido amplo, criando diferenciadas possibilidades e limites em seus processos de transição para a vida adulta. 0

\footnotetext{
${ }^{5}$ A diminuição das populações rurais e as precárias condições de tráfego das estradas têm implicado a redução das linhas de ônibus que interligam espaços rurais e cidades da região.
} 
trabalho familiar, socialmente percebido como "ajuda", do qual jovens rurais são solidariamente convocados a participar, seja nas atividades produtivas, seja nas domésticas, torna-se um traço marcante da identidade da família e das normas de socialização das novas gerações. Sob essa perspectiva, o trabalho ainda configura-se como importante fator identitário da juventude rural, embora nem sempre integrando projetos que visem à continuidade da agricultura familiar (WEISHEIMER, 2019). Segundo Marin (2019), o trabalho torna-se, então, elemento central na compreensão da juventude rural, especialmente pela tessitura das relações sociais e produtivas no âmbito da família, das relações de trabalho assalariadas e até mesmo das estratégias de continuidade dos estudos escolares.

Na valorização da autonomia do trabalho e na constituição individualizada do trabalhador, jovens rurais não descartam possibilidades de inserção laboral em outras esferas produtivas, especialmente nos contextos contemporâneos marcados pela intensa integração socioeconômica entre capitais industriais, financeiros, comerciais, agrícolas e de serviços. No território em estudo, especialmente nas últimas décadas, o aprofundamento das trocas de bens e serviços entre os setores do capital ampliou as oportunidades para jovens rurais agregarem-se em trabalhos assalariados, em relações formais ou informais, temporárias ou permanentes. As diferenciadas ocupações laborais tornam-se reveladoras da condição social dos jovens rurais, na medida em que evidenciam não somente as distintas possibilidades de inserção no mercado de trabalho e estratégias de transição para a vida adulta, mas, também, conforme estudo de Spanevello (2008), realizado em municípios da região central do Rio Grande do Sul, dos múltiplos limites para a viabilização dos processos de sucessão hereditária nas famílias de agricultores, decorrentes de fatores econômico-produtivos - a exemplo da pequena quantidade de terra, da baixa qualidade da terra, da baixa renda derivada das diferenças entre custos de produção e preços dos produtos agrícolas, das perdas por sinistros ambientais, do processo tardio de transmissão patrimonial, dentre outros -, bem como de fatores subjetivos relacionados às percepções negativas da ocupação agrícola e da permanência na agricultura familiar.

As dinâmicas socioprodutivas do território em estudo foram alteradas em graus e intensidades variadas, especialmente pela introdução de máquinas e equipamentos agrícolas que reduzem as demandas de força de trabalho. Mesmo que a incorporação de tecnologias transforme as tradicionais formas de organização do trabalho familiar, existem atividades produtivas altamente dependentes de mão de obra, a exemplo do cultivo de tabaco, importante produto mercantil de agricultores familiares que sempre demanda trabalhadores assalariados. Nesse sentido, agricultores familiares estão inseridos em contextos socioprodutivos complexos e diversificados, que oscilam desde situações de demanda de contratação de trabalhadores assalariados, especialmente quando a força de trabalho familiar é insuficiente para a execução de determinadas tarefas, notadamente a colheita, passando por situações em que integrantes das famílias procuram inserção em trabalhos assalariados. As diferenciadas estratégias de trabalho familiar e trabalho assalariado, em vez de antagônicas, complementam-se, possibilitando a transição de posições, ora de contratantes, ora de contratados. 
De fato, os jovens rurais pesquisados procuram estabelecer relações de trabalho assalariadas. Quantitativamente, do total de 191 jovens respondentes, 55\% informaram que têm rendas próprias e, entre estes, $35 \%$ obtêm sua renda pela incorporação no mercado de trabalho assalariado, em relações formais ou informais, existentes em suas comunidades ou nos centros urbanos próximos. Os arranjos pessoais e familiares, combinados com as oportunidades do mercado de trabalho, são balizadores de estratégias de assalariamento dos jovens rurais, com vistas ao atendimento de diferenciadas expectativas sociais que perpassam pela garantia da continuidade do estudo, complementação da renda familiar, realocação da força de trabalho familiar excedente ou construção de trajetórias profissionais fora da agricultura familiar.

Alguns jovens rurais entrevistados valorizam o trabalho assalariado mesmo com a precarização das relações de trabalho e os contratos temporários, pela necessidade de obter seus próprios ganhos monetários ou ampliar a renda familiar. Os dados quantitativos indicam que $28 \%$ das famílias têm rendas provenientes de trabalhos assalariados, formais ou informais, enquanto $12 \%$ são beneficiárias de programas de transferência de renda. Isso significa que parcelas consideráveis de famílias pesquisadas não conseguem gerar rendas satisfatórias nas atividades agrícolas, daí a necessidade de complementação com assalariamento e políticas de combate à pobreza.

A escassez de terra, em grande medida, propulsiona os jovens rurais ao trabalho assalariado pelas dificuldades de geração de renda satisfatória e de absorção da força de trabalho na unidade de produção familiar. Conforme dados quantitativos, cerca de 7\% das famílias não têm terra, 33\% têm entre 1 e 10 hectares de terra e 31\% têm entre 11 e 30 hectares. Em termos práticos, para além das recorrentes áreas montanhosas e pedregosas, baixa qualidade dos solos, inadequada localização da terra e limitações de uso definidas pelas legislações ambientais, essas exíguas extensões de terra dificilmente cumprem a função de gerar trabalho e renda para satisfazer as necessidades familiares.

Os jovens integrantes de famílias constrangidas pela falta de terra enfrentam sérias dificuldades para permanecer nas atividades agropecuárias, daí que contínuos fluxos migratórios representam sonhos de melhores condições de vida, pois "tem propriedade que não tem no que trabalhar. São propriedades menores e não tem serviço para ficar. Daí tem que sair para a cidade procurar emprego" (Laura, 21 anos, Agudo). A migração, em busca de ocupações laborais assalariadas, torna-se condicionante para alocação da força de trabalho familiar excedente. As situações de crise, contudo, desencadeadas pelo endividamento ou sinistros ambientais, também empurram os jovens rurais ao trabalho assalariado. $O$ depoimento a seguir elucida:

Já trabalhei fora para ajudar nos custos da nossa casa, pois tem épocas que não têm muito serviço na propriedade. E até mesmo, muitas vezes, a gente faz os afazeres em fim de semana pra no dia de semana trabalhar fora para ter uma melhor renda. Têm épocas de muita seca ou muito chuvoso que as plantações são muito prejudicadas e no final a renda não é tão boa assim. Daí, tem que trabalhar pra fora pra tentar uma outra renda para ajudar nos custos (Flávia, 26 anos, Toropi).

O assalariamento de jovens rurais vincula-se, mormente, aos contextos de pobreza familiar e de baixa escolaridade. Nessas situações, as narrativas socialmente construídas também decantam a "melhoria das condições de vida", como contraponto aos diversos limites da realização do trabalho familiar e constrangimentos enfrentados no 
espaço familiar, fazendo com que a experiência da migração torne-se possibilidade de objetivação do trabalhador autônomo. A incorporação em trabalhos assalariados é percebida, então, como uma saída honrosa para os jovens rurais empobrecidos, especialmente quando as vinculações se realizam com registro em carteira de trabalho. Em estudo na região do Baixo São Francisco sergipano, Mota (2005) notou que os trabaIhadores costumam valorizar a incorporação em relações de trabalho assalariado formalizadas, especialmente pela segurança proporcionada pelo salário por períodos mais prolongados e pelas melhores possibilidades de programação da vida financeira, bem como pelos benefícios sociais e trabalhistas assegurados pela legislação. Esses tão desejados vínculos legais representam a celebração da aprovação profissional do trabalhador, além de produzirem valiosos testemunhos de trajetórias distintas em relação aos demais trabalhadores desprotegidos dos amparos legais.

Tomando como parâmetro realidades de Estados do sul do país, Stropasolas (2006) e Brumer (2007) notaram que as agregações de jovens rurais em trabalhos assalariados podem viabilizar o atendimento de suas variadas necessidades, que nem sempre podem ser atendidas sob as condições de dependência familiar. Os jovens valorizam a conquista do próprio dinheiro para satisfazer suas necessidades de consumo e também de autonomia pessoal, que podem revelar confrontos com as hierarquias familiares. Stropasolas (2006) frisa que as motivações migratórias também estão associadas ao desejo de maior liberdade para viver suas próprias experiências e à busca por direitos de cidadania e demais recursos e serviços sociais, disponibilizados nas cidades por instituições públicas ou privadas, seja na área de educação, transporte, lazer, comunicação ou saúde.

Ademais, jovens rurais valorizam experiências no mercado de trabalho assalariado pela possibilidade de aumentar seu nível de conhecimentos, ampliar as redes de relações pessoais, melhorar habilidades pessoais e acumular experiências de vida. Acreditam, portanto, que o trabalho fora de casa é fundamental para torná-los mais sociáveis e conectados com as mudanças do mundo contemporâneo, conforme depoimento oral:

Eu trabalhei numa cerealista, fazia a classificação de grãos. Não era uma parte técnica, mas era serviço. Não vou dizer que foi serviço ruim, tinha um certo esforço físico, mas era bom. Tava sempre no dia a dia com pessoas diferentes, produtor. Era bom, eu gostava. Eu não vou dizer que foi ruim porque aprendi bastante coisa. Pra fora, sabe, a gente vai viver um outro dia a dia, sempre esse movimento. Eu gostei, pra mim foi bom (Ricardo, 24 anos, Júlio de Castilhos).

Assim, os sonhos de ampliação de renda, de experiências e de conhecimentos, podem favorecer a decisão dos jovens pelo trabalho assalariado. As vinculações em relações assalariadas, porém, não são escolhas unidirecionais nem mesmo definitivas, daí que as experiências laborais dos jovens rurais podem assumir caráter temporário ou permanente. Em contextos rurais do sul da Bahia, conforme pesquisa de Nogueira (2013), os fluxos migratórios de jovens em busca de trabalho assalariado também podem constituir-se em estratégias de formação de poupanças para providenciar o futuro retorno à produção de base familiar. Woortmann (1990), a partir do estudo de camponeses de Sergipe, já havia compreendido as diferenciadas experiências migratórias colocadas em prática pelos camponeses e os seus distintos significados atribuídos, destacando que as experiências migratórias vividas pelos jovens, em busca de ganhos 
monetários em trabalhos assalariados, podem integrar estratégias de reprodução social e ritos de passagem para a vida adulta. Assim, a migração e o assalariamento podem ser consequências da "inviabilização das condições de existência", mas também podem representar práticas de reprodução social dos agricultores. No território em estudo, os jovens rurais expressaram complexos projetos relacionados aos estudos, trabalho assalariado, formação de poupanças e futuros investimentos na propriedade, na expectativa de retorno ao campo:

Do que já estudei, posso unir o útil ao agradável. Atualmente, trabalho no Sindicato dos Trabalhadores Rurais, como técnica. Mas já concilio muito bem isso, nos dias de semana aqui, finais de semana lá, vai arrumando, a gente vai ajeitando. Na verdade, esse trabalho seria uma ajuda extra para mim investir lá; tenho um dinheirinho a mais todo mês que posso investir na propriedade (Viviane, 24 anos, Tupanciretã).

$\mathrm{Na}$ diversidade de projetos e trajetórias de vida, todavia, entre os jovens entrevistados, há uma tendência aos empregos assalariados em situação de limite da reprodução familiar de agricultores. As jovens rurais mostram-se mais inclinadas à inserção no mercado de trabalho assalariado como caminho para não reproduzir a profissão das mães. Trabalhar fora de casa torna-se, então, uma alternativa para obtenção de renda própria, que possibilita a conquista da autonomia pessoal e facilita a continuidade dos estudos escolares, tendo no horizonte ocupações laborais mais qualificadas e mais bem remuneradas:

Eu queria aumentar minha renda. Trabalhar na agricultura é bom, mas é aquela coisa: tem que gostar. É sempre a mesma rotina. Eu acredito que eu não me adequaria muito a essa rotina... Quero ter uma melhoria de vida. Assim, no tempo, eu não queria seguir a mesma profissão dos meus pais. Eu não quero ser agricultora. Eu quero buscar outra oportunidade, estudar e seguir depois (Talita, 18 anos, Agudo).

Em relatos orais, jovens rurais revelam múltiplas razões para justificar sua inserção em trabalhos fora das unidades produtivas familiares. Isso, porém, não significa que eles encontrem facilidades para agregações no mercado de trabalho assalariado dos municípios pesquisados, pois, por um lado, existem poucas ofertas de vagas de trabalho e, por outro, os salários são baixos em relação aos custos de vida na cidade. A partir da realidade de Agudo, um jovem rural relata constrangimentos dos que tentam inserir-se em trabalhos assalariados: "Até que tem bastante procura para trabalhar na cidade. Mas, geralmente, o pessoal faz o teste, fica aqui um mês e depois vai embora de novo, até por causa de que na cidade, comparado ao interior, o custo de vida é mais alto" (Davi, 29 anos).

Por fim, as agregações de jovens rurais no trabalho assalariado, temporário ou permanente, em relações formais ou informais, revelam os múltiplos limites da reprodução familiar de agricultores. O assalariamento, contudo, nem sempre é caminho sem retorno ao trabalho familiar, uma vez que pode representar alternativas inerentes à constituição de diversos patrimônios, consubstanciados na terra, nos instrumentos de trabalho e no acúmulo de novos saberes e visões de mundo, considerados necessários para a instalação do futuro produtor agrícola independente. 


\section{JOVENS RURAIS NA CONSTRUÇÃO DA SUCESSÃO HEREDITÁRIA}

Parcelas de jovens rurais procuram orientar seus processos de emancipação pessoal pelo trabalho na agricultura familiar. Em termos quantitativos, cerca de $31,4 \%$ dos jovens pesquisados afirmam que têm rendas próprias provenientes de atividades agrícolas. Possivelmente esses estratos de jovens representem os sucessores na agricultura familiar. Na constituição de futuros agricultores familiares, esses jovens enfrentam três problemas fundamentais: a transmissão patrimonial familiar, os limites no acesso às políticas públicas e as vinculações mercantis nos complexos agroindustriais.

A transmissão patrimonial, especialmente da terra, tem sido questão marcada por tensões e conflitos familiares. A terra, como já apontado anteriormente, é limitante para absorção de todos os filhos, daí que a escolha resulta em herdeiros e deserdados da terra, posto que estes últimos também devem ser recompensados. "Dar estudos" é estratégia de compensação dos filhos e filhas não contemplados com herança da terra. Embora, no entanto, padrões comportem variações, a transmissão patrimonial da terra costuma ser protelada durante a vida dos chefes de família, deixando em aberto aos herdeiros as decisões sobre a partilha dos bens, o que pode gerar insegurança, tensões e conflitos entre os herdeiros. Em conversas informais, possibilitadas ao longo do projeto de extensão universitária, representantes de sindicatos de trabalhadores rurais relatam que se tornou recorrente a irregularidade fundiária entre famílias de agricultores, em razão das dificuldades de arcar com possíveis custos advocatícios e impostos de transferência do imóvel ou da falta de consenso entre os herdeiros acerca das partilhas.

Vale ressaltar que a transmissão do patrimônio fundiário e o parcelamento contínuo da propriedade da terra, são problemas recorrentes entre os camponeses, conforme estudos realizados em diferentes contextos histórico-sociais do Brasil. Moura (1978), a partir de experiências de camponeses de Minas Gerais, afirma que os sistemas de herança da terra são alicerces dos processos de reprodução social das famílias camponesas, cujos fundamentos estão assentados nos costumes locais e na lei. Neste contexto, a autora notou a existência de complexas e diferenciadas formas de transmissão do patrimônio fundiário, que podem revelar uma racionalidade própria, construída a partir dos costumes, com propósitos de viabilizar a reprodução social dos camponeses e garantir a continuidade dos estabelecimentos. Em outras situações, todavia, os códigos jurídicos tornavam-se orientadores das práticas de herança da terra, descontruindo os sistemas de partilhas tradicionais dos camponeses (MOURA, 1978). A partir do estudo sobre camponeses descendentes de imigrantes alemães do Vale do Itajaí-Mirin, Santa Catarina, Seyferth (1985) afirmou que a transmissão do patrimônio fundiário também se orientava por normas do direito costumeiro, reconhecidas com base na tradição familiar e comunitária, com vistas a preservar a propriedade familiar e evitar a excessiva fragmentação pela exclusão de um ou mais herdeiros. Seyferth (1985) observou ainda uma diversidade de sistemas de partilhas, que oscilam desde a herança impartível - na qual somente um dos filhos torna-se herdeiro da terra - até a partilha da terra entre os herdeiros - na qual todos têm igualdade de direitos.

Woortmann (1995), em estudo com descendentes de imigrantes alemães do Rio Grande do Sul, evidenciou certa predominância na escolha do filho mais velho para a continuidade da propriedade familiar. Desta forma, o padrão sucessório predominante 
tendia a privilegiar um único sucessor, em decorrência da pequena extensão da terra, produzindo a exclusão dos demais herdeiros, como forma de garantir a continuidade do estabelecimento familiar. No entendimento de Woortmann (1995, p. 314), portanto, "o deserdado é o indivíduo produzido pela totalidade interna para viver no mundo externo."

Já entre camponeses descendentes de imigrantes italianos da região da Serra Gaúcha, Santos (1984) e Carneiro (2001) notaram que os escolhidos como sucessores e herdeiros do patrimônio territorial eram, com predominância, os filhos mais novos, reproduzindo o sistema conhecido como "minorato". A filha mulher, normalmente, era excluída da herança da terra e, por ocasião do casamento, recebia somente um dote que, segundo Carneiro (2001, p. 35), constituía-se "uma maneira de compensá-la pela desistência da sua parte da herança em terra. Mas sob a justificativa de que ao se casar estaria protegida economicamente pelo marido; o valor do dote era sempre inferior ao valor recebido pelos filhos como herança."

As formas de transmissão patrimonial, como ressalta Carneiro (2001), são variáveis conforme os contextos econômicos, histórico-sociais, espaciais, institucionais e familiares. As diferenciadas práticas de transmissão patrimonial estão ancoradas em distintas lógicas de reprodução social, que devem ser entendidas não apenas como resultado das orientações jurídicas, mas, sobretudo, dos diferentes sistemas tradicionais de partilhas e das diferenciadas estratégias de reprodução socioeconômica dos agricultores familiares. Na Região Central do Rio Grande do Sul, os padrões de transmissão do patrimônio combinam múltiplos fatores e estratégias para evitar o fracionamento excessivo da terra e garantir a reprodução familiar. Retoricamente, as normas são fundamentadas no sistema de partilha entre todos os herdeiros, mas, em termos práticos, somente alguns tornam-se herdeiros, com vistas a garantir a propriedade da terra e a viabilização dos sucessores. Aqueles jovens rurais, portanto, que possivelmente serão excluídos da partilha da terra, tendem a objetivar os estudos escolares, a migração e a incorporação no trabalho assalariado como saídas plausíveis e moralmente aceitáveis na construção de seus projetos de emancipação pessoal.

Agrega-se, ainda, como já analisado por Paulilo (2017) em realidades rurais de Santa Catarina, o problema do adiamento da transferência patrimonial e da responsabilidade pela organização e administração das atividades produtivas familiares. Por um lado, o aumento da expectativa de vida das populações rurais tem contribuído para que chefe de família permaneça por mais tempo na direção da unidade produtiva, protelando sua abdicação em favor dos herdeiros; por outro, a transferência aos herdeiros não está associada à aposentadoria do chefe da família, uma vez que é percebida como complementação de renda familiar e não como momento oportuno para a transmissão da unidade produtiva. Dessa forma, o pai permanece na condição de agente central nas tomadas de decisão da organização produtiva e administrativa da propriedade familiar, limitando o protagonismo dos jovens agricultores.

Se as famílias limitam a afirmação de sucessores, os jovens rurais não encontram grandes alentos na esfera das políticas estatais. Não obstante a edição de providências para facilitar a instalação de sucessores na agricultura familiar, instituições e políticas públicas não conseguem mudar significativamente a realidade dos jovens rurais. To- 
mando como parâmetro o estudo das políticas públicas de acesso a terra, crédito rural e serviços de extensão rural, torna-se gritante o limitado alcance na vida dos jovens rurais pesquisados.

Particularizando a questão da terra, os dados quantitativos indicam que apenas 3,7\% das famílias dos jovens foram beneficiadas por programas de reforma agrária, embora, como apontado anteriormente, $40 \%$ das famílias tenham menos de dez hectares de terra. Os critérios de seleção dos programas de reforma agrária, todavia, priorizam os adultos como beneficiários; em situações muito excepcionais, os jovens rurais podem ser contemplados com um lote de terra (INCRA, 2011). Além disso, como destacou Neves (2009), os lotes de terra nos programas de assentamento rural são idealizados para a garantia de níveis de produtividade suficientes para o bem-estar e prosperidade de uma família nuclear, isto é, formada pelas gerações de pais e filhos. O alcance da idade adulta impõe aos filhos as experiências migratórias, a fim de que, "mais uma vez, cada família viva seu fluxo de reprodução geracional em uma família conjugal".

No investimento para permanência no campo, jovens rurais aderiram ao Programa Nossa Primeira Terra - modalidade de crédito fundiário destinada à juventude rural. Os números de beneficiários não são expressivos - apenas $2,2 \%$ da amostragem quantitativa -, mas revelam a disposição dos jovens no enfrentamento da falta de terra, pela adesão a essa política de reforma agrária de mercado. Esses jovens, no entanto, já se instalam sob o signo do endividamento ao sistema bancário. Ao mesmo tempo em que o crédito fundiário possibilita acesso a terra, os jovens devem destinar parte dos ganhos monetários para quitar suas dívidas bancárias, com repercussões sobre os investimentos produtivos e a renda familiar.

A política de crédito rural também não cumpre seu objetivo primordial de produzir jovens sucessores na agricultura familiar. O Pronaf Jovem, criado em 2003 como linha do Programa Nacional de Fortalecimento da Agricultura Familiar (Pronaf), foi concebido como política creditícia específica para as gerações juvenis, com vistas a desencadear investimentos para criar ou aprimorar atividades produtivas, conjugados com a qualificação socioprofissional. Os critérios normativos do Pronaf Jovem anunciam o desenvolvimento de redes de relações favoráveis à inserção da juventude rural, na expectativa de projetar uma geração inserida nos mercados, protagonista e qualificada profissionalmente para a assunção de posições de liderança nos processos de desenvolvimento rural sustentável (MARIN, 2020). No território em estudo, conforme dados quantitativos, nenhum jovem conseguiu acessar o Pronaf Jovem do universo de 191 respondentes. Isso significa que essa política de crédito para a juventude rural não se objetiva na realidade, pois, entre os jovens rurais pesquisados, predominam o desconhecimento e a desinformação acerca do Pronaf Jovem, as dificuldades de atendimento das exigências burocráticas e a discriminação de agentes do sistema bancário. Dois jovens rurais entrevistados e seis jovens da amostragem quantitativa, no entanto, acessaram outras linhas do Pronaf. Esses jovens eram casados e tinham mais de 25 anos de idade. Podemos aventar que o estado civil e o estrato etário com tendência para a vida adulta facilitam a obtenção da própria Declaração de Aptidão ao Pronaf (DAP), a isenção de documentos comprobatórios da realização dos cursos de qualificação e a aproximação e credibilidade junto aos funcionários dos bancos. 
No que se refere aos serviços de extensão rural, nos municípios pesquisados é notável a fragilidade das redes institucionais de transmissão de conhecimentos e tecnologias, especialmente para os jovens rurais que pretendem constituir-se como sucessores na agricultura familiar. Cerca de $77 \%$ dos jovens respondentes do questionário informaram que suas famílias recebem serviços de assistência técnica e extensão rural, mas esporadicamente e mediante solicitações. Ademais de descontínuos, os serviços são destinados aos agricultores familiares adultos. Em diversas atividades desenvolvidas no projeto Emater-RS/UFSM/IFFar, ficou claro que os agentes de extensão rural ainda não tinham incluído os jovens em suas programações. Mesmo presentes nas famílias atendidas, eles permaneciam "invisíveis" para as equipes de extensão rural.

Em suma, as políticas públicas de acesso a terra, crédito rural e extensão rural, nos documentos e discursos oficiais, sempre pontuadas como fundamentais nos processos de sucessão na agricultura familiar, não conseguem mudar a realidade da maioria dos jovens rurais pesquisados. $O$ depoimento de um jovem rural ilustra a fragilidade das políticas públicas destinadas aos jovens que desejam permanecer na agricultura:

O governo debate, debate, tanto o governo municipal, os outros governos debatem que tem que permanecer o jovem no campo, pro campo continuar produzindo $e$ tal. Mas eu não vejo um projeto do governo mesmo para incentivar o jovem a ficar aqui. No nosso Estado, eu não vejo. Quero que o governante mostre o projeto que eles têm: "esse projeto vai ajudar o jovem a ficar". Eu nunca vi e acho que não tem (Ricardo, 24 anos, Júlio de Castilhos).

Pelo exposto, existem disjunções entre o propugnado nos documentos formais e discursos políticos e as experiências vividas pelos jovens rurais. Se as políticas públicas não atendem satisfatoriamente, quais as estratégias articuladas pelos jovens em processos de sucessão na agricultura familiar?

Elementos explicativos para tal questão podem ser encontrados nas atividades produtivas das famílias dos jovens rurais. Embora seja comum o desenvolvimento de mais de uma atividade, os principais produtos mercantis, conforme dados quantitativos, são o fumo (para $30,4 \%$ das famílias dos jovens rurais pesquisados), milho (12,6\%), leite $(11,5 \%)$, gado de corte $(10,5 \%)$, soja $(10,5 \%)$, arroz $(6,3 \%)$, frutas $(4,6 \%)$, leguminosas $(3,2)$, feijão $(2,5 \%)$, mandioca $(2,1 \%)$, suínos e ovinos $(1,5 \%)$, considerando que $4,3 \%$ não responderam. Vale notar que os principais produtos de interesse mercantil são viabilizados pela integração dos agricultores familiares aos complexos agroindustriais.

Em termos produtivos, desde a década de 60 do século 20, as formas de organização produtiva dos agricultores familiares sofreram profundas transformações, provocadas pela integração aos complexos agroindustriais, que estreitaram, conforme proposições de Graziano da Silva (1998), as inter-relações entre os setores industriais, financeiros, comerciais, agrícolas e de serviços. A integração de capitais aumentou a circulação de produtos, recursos financeiros e serviços, redefinindo os padrões tecnológicos, as formas de organização do trabalho e as relações produtivas, que passaram a ser regulamentadas por contratos agrários. A integração em poderosas cadeias do complexo agroindustrial do fumo, soja, arroz, milho, leite e carnes de bovinos, suínos e aves, mais do que as produções orientadas aos mercados de circuitos curtos, tornou-se alternativa para viabilizar as atividades produtivas daqueles jovens agricultores em processo de sucessão hereditária. 
Nas produções integradas aos complexos agroindustriais, os agricultores familiares investiram em máquinas, implementos, instalações agrícolas e, em alguns casos, animais geneticamente melhorados, bem como acumularam habilidades, conhecimentos técnicos e mercadológicos. Fundamentados em experiências e investimentos familiares, acumulados pela integração agroindustrial, os jovens procuram constituir-se como sucessores na agricultura familiar. Do mesmo modo, pela integração nas cadeias produtivas, os jovens acessam recursos financeiros, tecnologias e insumos agrícolas, serviços de assistência técnica e, sobretudo, mercado para a produção agrícola.

Se a integração agroindustrial proporciona inserções produtivas, as condições impostas pelos distintos setores dos complexos agroindustriais pesam desfavoravelmente aos jovens rurais. Os jovens criticam as relações impostas pelas empresas, tanto pelos preços elevados para as máquinas, insumos agrícolas e serviços, quanto pelas oscilações e rebaixamentos dos valores dos produtos agrícolas. $O$ depoimento de uma jovem rural ilustra as dificuldades impostas pelo mercado organizado por empresas integrantes dos complexos agroindustriais, que resultam em pequenas margens de ganhos econômicos dos agricultores familiares:

Pra nós aqui, também o aumento exagerado dos insumos. Isso traz um custo muito grande para lavoura e não compensa no produto final, porque na hora que tu pensa que tu vai pegar aquilo, se tu for analisar, botar tudo no papel, quase empata dinheiro ou sobra pouco, porque o produto final eu acho muito desvalorizado (Mariana, 27 anos, Júlio de Castilhos).

As condições técnicas produtivas e as trocas mercantis desiguais, impostas por distintos agentes econômicos integrantes do complexo agroindustrial, são poderes que reduzem a autonomia e expropriam os jovens rurais e suas famílias. Tais mecanismos, por fim, diminuem a renda familiar e dificultam a criação de poupanças, colocando sérios limites aos projetos de emancipação dos jovens rurais. A expropriação dos produtos agrícolas ou, como denunciado por jovens entrevistados, as situações de não pagamento da produção vendida à agroindústria, portanto, tornam-se pontos de tensões e conflitos entre jovens agricultores:

Pra começo, o melhor pagamento do produto seria uma mão na roda, valorização do produto. Como eu disse, aqui, tu trabalha, trabalha, trabalha, trabalha... Às vezes, dá até aquele desânimo na gente porque tu pensa: "trabalhei, tá, e agora? Pra isso? Tão pouco?" Podia pagar um pouco mais, né? A gente planta fumo, vai lá na firma, briga pelo preço, passa aquele fumo na esteira. A gente tá brigando com os compradores lá dentro, daí eles param a esteira. Não adianta brigar: ou tu traz o fumo embora de volta e deixa no galpão ou tu tem que se contentar. Só que eu disse: Enquanto eles tão lá trabalhando bonitinho, como é que foi que aquele produto chegou lá? Será que eles, todo mundo que tá lá, realmente sabe como é que aquele fardo de fumo chegou lá? Como é que aquela bolsa de soja chegou lá? Não sabe da onde que sai, como sai. Então, eu digo assim: a valorização do produto já seria um grande feito pro jovem ficar aqui no meio rural (Mariana, 27 anos, Júlio de Castilhos).

A justa remuneração dos produtos agrícolas é questão central para os jovens agricultores familiares. As integrações mercantis proporcionadas pelos complexos agroindustriais estão fundamentadas nos signos da subordinação e expropriação dos frutos do trabalho, que dificultam a formação de poupanças e melhorias na estrutura das pro- 
priedades familiares e na condição de vida dos jovens rurais. Isso significa que as agroindústrias viabilizam inserções produtivas dos novos agricultores familiares, mas em relações de subjugação e expropriação do trabalho.

Agentes sociais, vinculados às instituições de desenvolvimento territorial, propugnam alternativas produtivas que reduzem a dependência das grandes empresas agroindustriais, especialmente no que se refere à cultura do tabaco. Não obstante, alguns jovens afirmam que não é fácil romper com o sistema de produção integrada e introduzir novas alternativas produtivas, conforme depoimento: "acredito que nosso lugar está numa monocultura do pequeno. Tu planta fumo, tu tem lucro. Tu planta outra coisa nem mercado tu consegue" (Mário, 26 anos, Mata).

A diversificação produtiva tornou-se tema de debate público, especialmente por ser região de cultivo do tabaco, em decorrência do Programa Nacional de Diversificação Produtiva em Áreas com Cultivo do Tabaco, instituído pelo Ministério do Desenvolvimento Agrário, a partir da ratificação da Convenção-Quadro para o Controle do Tabaco, em 2005. Desde então, diversos agentes sociais procuraram propor e experimentar novas alternativas de inserção produtiva e mercantil. Agricultores que pretendem legalizar agroindústrias familiares, porém, se depararam com limites impostos pela legislação sanitária dos produtos de origem animal e vegetal. A atuação de agentes sanitários, pautada na apreensão de produtos e multa aos agricultores não legalizados, desestimula a proposição de alternativas de agroindústrias familiares e favorece as migrações de jovens rurais, conforme depoimento:

Trazer novas alternativas de produção. O pessoal é bastante dependente do fumo. Mas eu vejo também que muitos ainda estão no interior, porque eles produzem pra vender no comércio local. Só que agora com fiscalização; no mês passado teve aquela fiscalização aqui em Agudo. Não sei se tu chegou a ver... Muitos: "ah, não vou ficar, o que eu vou produzir eu não vou poder vender." Acho que é uma coisa que também poderia ser procurado alternativas para esses produtores, pra conseguirem vender aqui no comércio local. Eles recolhem os produtos e não deixam vender, isso é uma coisa que desanima. "Ah, vou produzir e não vou poder vender" (Talita, 18 anos, Agudo).

Pelas integrações agroindustriais, os jovens rurais e suas famílias acessam recursos financeiros, tecnologias, assistência técnica e mercado. Dessa forma, conseguem viabilizar atividades produtivas e comerciais, não obstante a subordinação e a expropriação do trabalho, que dificultam seus projetos de emancipação social e produtiva.

\section{CONSIDERAÇÕES FINAIS}

Neste artigo, a juventude rural foi considerada uma categoria social, demarcada por critérios etários-biológicos e, sobretudo, pelas teias de relações sociais em que os jovens estão inseridos em seus contextos históricos e espaciais. Sob essa perspectiva, a juventude rural foi analisada a partir das particularidades do conjunto de relações sociais, dos processos de socialização, dos investimentos para enquadramento institucional dos jovens, das múltiplas formas de inserção socioeconômica, das relações de gênero, bem como dos próprios parâmetros que os jovens constroem da realidade so- 
cial, de suas práticas sociais e visões de mundo. A análise das relações que interligam os jovens rurais e o mundo que os cerca foi fundamental para compreender tessituras de diferenciados projetos de emancipação social para a transição à vida adulta.

Por meio de apoio familiar, vinculações institucionais, acesso às políticas públicas, agregações laborais e trabalho na agricultura familiar, os jovens rurais vivem sua juventude de maneiras distintas e constroem estratégias diversificadas para construir seus projetos de emancipação pessoal. Parcelas significativas de jovens rurais investem nos estudos, com a crença de que as instituições escolares são lugares que concedem saberes, qualificações e títulos fundamentais para a construção de trajetórias socioprofissionais fora da agricultura familiar. Jovens rurais, especialmente aqueles que vivenciam sérias dificuldades para viabilizar a reprodução social na agricultura familiar, tecem projetos de emancipação pessoal pela inserção no trabalho assalariado, mas também podem representar estratégias para a continuidade dos estudos ou a instalação do futuro produtor agrícola independente. Outros estratos de jovens rurais constroem a autonomia social pela sucessão hereditária na agricultura familiar por meio de integrações agroindustriais, que viabilizam a produção e inserções mercantis, mas sob as marcas da subordinação e da expropriação.

A maioria dos jovens pesquisados não estabelece projetos profissionais na agricultura familiar, levando-se em consideração as atuais vinculações nas instituições escolares e no mercado de trabalho assalariado. Os projetos profissionais desses jovens rurais são tecidos com base nas condições objetivas e subjetivas da reprodução nas unidades de produção familiar. Objetivamente, a reprodução familiar dos agricultores está limitada pelo precário acesso à propriedade da terra e aos recursos materiais produtivos, bem como pelos processos de subordinação e expropriação do trabalho vividos nas integrações agroindustriais. Subjetivamente, a recusa de jovens rurais na reprodução social na agricultura familiar explica-se pelas avaliações negativas do trabalho e da vida na agricultura familiar, pelas posições subalternas nas hierarquias familiares e pela falta de autonomia na gestão da unidade produtiva. A precariedade material e a desvalorização das condições de vida e trabalho motivam, em grande medida, a busca por estudos escolares ou trabalhos assalariados, que confluem em contínuas migrações de jovens rurais.

Esse complexo panorama reflete diversificadas limitações vividas pelos jovens rurais do Território da Região Central do Rio Grande do Sul, para criar condições de vida e de trabalho satisfatórios na agricultura familiar e viabilizar seus processos de transição para a vida adulta. Não obstante, jovens rurais permanecem na agricultura familiar e cultivam sonhos de melhores inserções econômicas e sociais. As instituições e os agentes de desenvolvimento territorial deveriam atender exatamente a esse segmento da juventude rural, desencadeando ações efetivas e articuladas para facilitar o acesso a terra, aos recursos materiais, aos conhecimentos, às alternativas produtivas e aos mercados, em contínuos investimentos para a construção da autonomia dos jovens rurais e da sucessão hereditária na agricultura familiar.

\section{REFERÊNCIAS}

ABRAMO, H. Debate. In: CASTRO, E. G.; CARNEIRO, M. J. (org.). Juventude rural em perspectiva. Rio de Janeiro: Mauad X, 2007. p. 67-71.

BARCELLOS, S. B. As políticas públicas para a juventude rural: o Pronaf Jovem em debate. Planejamento e Políticas Públicas, n. 48, jan./jun., p. 149-173, 2017. 
BORGES, C. C.; MAGALHÃES, A. S. Transição para a vida adulta: autonomia e dependência na família. PsiCo, Porto Alegre, PUC-RS, v. 40, n. 1, p. 42-49, jan./mar. 2009.

BOURDIEU, P. La “jeunesse” n'est pas qu'un mot. Questions de sociologie. Lonrai: Les Éditons de Minuit, 2011. p. 143-154.

BRASIL. Decreto 7.234, de 19 de julho de 2010 - Dispõe sobre o Programa Nacional de Assistência Estudantil (PNAES). Brasília: Presidência da República, 2010.

BRASIL. Decreto 8.736, de 03 de maio de 2016 - Institui o Plano Nacional de Juventude e Sucessão Rural. Brasília: Presidência da República, 2016.

BRASIL. Estatuto da Juventude: atos internacionais e normas correlatas. Brasília: Senado Federal; Coordenação de Edições Técnicas, 2013. Disponível em: https://www2.senado.leg.br/bdsf/bitstream/handle/ id/509232/001032616.pdf. Acesso em: 10 dez. 2018.

BRUMER, A. A problemática dos jovens rurais na pós-modernidade. In: CASTRO, E. G.; CARNEIRO, M. J. (org.). Juventude rural em perspectiva. Rio de Janeiro: Mauad X, 2007. p. 35-51.

BRUMER, A. Gênero e agricultura: a situação da mulher na agricultura do Rio Grande do Sul. Revista Estudos Feministas, Florianópolis, v. 12, n. 1, p. 205-227, 2004.

CARNEIRO, M. J. Herança e gênero entre agricultores familiares agricultores familiares. Revista Estudos Feministas, Florianópolis, v. 9, n. 2, p. 22-55, jun./dez. 2001.

CARNEIRO, M. J. Juventude e novas mentalidades no cenário rural. In: CASTRO, E. G.; CARNEIRO, M. J. (org.). Juventude rural em perspectiva. Rio de Janeiro: Mauad X, 2007. p. 53-66.

CASTRO, M. E. Balanço e perspectivas. In: CARNEIRO, M. J.; CASTRO, E. G.(org.). Juventude rural em perspectiva. Rio de Janeiro: Mauad X, 2007. p. 128-135.

EMATER-RS/UFSM/IFFar. Juventude rural: estudo no Território da Região Central do Rio Grande do Sul. Porto Alegre: Emater-RS, 2017.

FEIXA, C. P. A construção histórica da juventude. In: CACCIA-BAVA, A.; FEIXA, C. P. GONZÁLES, Y. C. (org.). Jovens na América Latina. São Paulo: Escrituras, 2004. p. 257-327.

FEIXA, C. P. De jóvenes, bandas y tribus. Barcelona: Editorial Ariel, 2006 a.

FEIXA, C. P. Generación XX: teorías sobre la juventud en la era contemporánea. Revista Latinoamericana de Ciencias Sociales, Niñez y Juventud, n. 2, v. 4, p. 21-46, 2006b. Disponível em: http://redalyc.uaemex. $\mathrm{mx} / \mathrm{src} /$ inicio/ArtPdfRed.jsp?iCve=77340202. Acesso em: $12 \mathrm{dez} .2018$.

FERREIRA, B.; ALVES, F. Juventude rural: alguns impasses e sua importância para a agricultura familiar. In: CASTRO, J. A.; AQUINO, L. M.; ANDRADE, C. C. Juventude e políticas sociais no Brasil. Brasília: Ipea, 2009. p. 243-258.

GRAZIANO DA SILVA, J. A nova dinâmica da agricultura brasileira. Campinas: Unicamp, 1998.

INCRA. Instituto Nacional de Colonização e Reforma Agrária. Incra abre consulta pública sobre critérios de seleção de beneficiários da reforma agrária. Brasília: Incra, 2011.

MARIN, J. O. B. Jovens mulheres rurais: tessituras de diferenciados projetos profissionais. In: COSTA, C.; MARIN, J. O. B. (org.). Gênero e campesinato no Sul do Brasil. Dominação masculina e transformação. Curitiba: CRV, 2018. p. 63-98.

MARIN, J. O. B. Juventudes rurais: processos sociais e temáticas de pesquisas. In: MARIN, J. O. B.; FROEHLICH. J. M. (org.). Juventudes rurais e desenvolvimento territorial. Santa Maria: Editora da UFSM, 2019. p. 35-66.

MARIN, J. O. B. Pronaf-Jovem: as disjunções entre o ideal e o real. Revista de Economia e Sociologia Rural. Brasília, v. 58, n. 2, p. 1-19, 2020. Disponível em: https://www.scielo.br/pdf/resr/v58n2/0103-2003-resr58-2-e187438.pdf. Acesso em: 3 maio 2020.

MDA. Ministério do Desenvolvimento Agrário. Sistema de Informações Territoriais. Composição Municipal do Território Região Central - RS. Brasília: MDA, 2016.

MOTA, D. M. Trabalho e sociabilidade em espaços rurais. Fortaleza: Banco do Nordeste do Brasil; Embrapa Tabuleiros Costeiros, 2005.

MOURA, M. M. Os herdeiros da terra: parentesco e herança. São Paulo: Hucitec, 1978.

NEVES, D. P. Agricultura familiar: quantos ancoradouros! In: FERNANDES, B. M.; MARQUES, M. I. M.; SUZUKI, J. C. (org.). Geografia agrária: teoria e poder. São Paulo: Expressão Popular, 2007. p. 211-270.

NEVES, D. P. Constituição e reprodução do campesinato no Brasil: legado dos cientistas sociais. In: NEVES, D. P. (org.). Processos de constituição e reprodução do campesinato no Brasil: formas dirigidas de constituição do campesinato. São Paulo: Unesp; Brasília: Nead, 2009. p. 303-323. V. II.

NOGUEIRA, V. S. Trabalho assalariado e campesinato: uma etnografia com famílias camponesas. Horizontes Antropológicos, Porto Alegre, v. 19, n. 39, p. 241-268, 2013. 
PAPPÁMIKAIL, L. Juventude(s), autonomia e sociologia: redefinindo conceitos transversais a partir do debate acerca das transições para a vida adulta. Sociologia - Revista da Faculdade de Letras da Universidade do Porto, v. XX, 2010, p. 395-410.

PAULILO, M. I. Mulheres rurais: quatro décadas de diálogo. Florianópolis: Editora UFSC, 2017.

PAULO, M. A. L. Juventudes rurais do Nordeste: as múltiplas realidades numa região de contrastes. In: MENEZES, M. A.; STROPASOLAS, V. L.; BARCELLOS, S. B. (org.). Juventude rural e políticas públicas no Brasil. Brasília: MDA, 2014. p. 234-250.

PICOLOTTO, E. L.; MARIN, J. O. B. Juventude rural: estudo na Região Central do Rio Grande do Sul. Rio de Janeiro: Bonecker, 2018.

SANT'ANA, R. B. Autonomia do sujeito: as contribuições teóricas de G. H. Mead. Psicologia: Teoria e Pesquisa, Brasília, v. 25, n. 4, p. 467-477, out./dez. 2009.

SANTOS, J. V. T. Colonos do vinho: estudo sobre a subordinação do trabalho camponês ao capital. São Paulo: Editora Hucitec, 1984.

SCHNEIDER, S. (org.). A diversidade da agricultura familiar. Porto Alegre Ed. UFRGS, 2006.

SEYFERTH, G. Herança e estrutura familiar camponesa. Boletim do Museu Nacional, Antropologia, Rio de Janeiro: UFRJ, n. 52, 1985.

SPANEVELLO, R. M. A dinâmica sucessória na agricultura familiar. 2008. 236 f. Tese (Doutorado em Desenvolvimento Rural) - Universidade Federal do Rio Grande do Sul, Porto Alegre, 2008.

STROPASOLAS, V. L. O mundo rural no horizonte dos jovens. Florianópolis: Ed. da UFSC, 2006.

WANDERLEY, M. N. B. Jovens rurais de pequenos municípios de Pernambuco: que sonhos para o futuro. In: CARNEIRO, M. J.; CASTRO, E. G. (org.). Juventude rural em perspectiva. Rio de Janeiro: Mauad X, 2007. p. 35-51.

WEISHEIMER, N. Estudo da situação juvenil na agricultura familiar do recôncavo da Bahia. In: ENCONTRO ANUAL DA ANPOCS, 37., 2013. Águas de Lindoia. Anais [...]. Águas de Lindoia: Anpocs, 2013.

WEISHEIMER, N. Jovens agricultores familiares: situação juvenil e projetos profissionais no Recôncavo da Bahia. In: MARIN, J. O. B.; FROEHLICH. J. M. Juventudes rurais e desenvolvimento territorial. Santa Maria: Editora da UFSM, 2019. p. 167-192.

WOORTMANN, E. F. Herdeiros, parentes e compadres: colonos do sul e sitiantes do Nordeste. São Paulo: Hucitec; Brasília: Edunb, 1995.

WOORTMANN, K. Migração, família e campesinato. Revista Brasileira de Estudos de População, Campinas, v. 7, n. 1, p. 35-53, jan./jun. 1990. 